\title{
A Review on Psychological Safety: Concepts, measurements, antecedents and Consequences variables
}

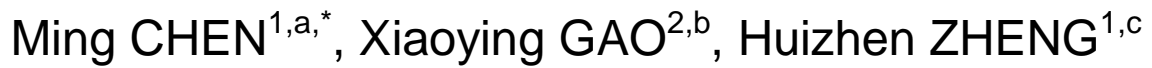 \\ and Bin RAN $^{3, d}$ \\ ${ }^{1}$ School of Business, Beifang University of Nationalities, Yinchuan 750021, China \\ ${ }^{2}$ School of Marxism, Beifang University of Nationalities, Yinchuan 750021, China \\ ${ }^{3}$ School of Business, Jilin University, Changchun130012, China
}

\begin{abstract}
As an important indicator of employees' psychological contract and organizational trust, psychological safety is a kind of safety awareness based on the psychological climate of certain events in organization, current scholars generally divided it into three levels: individual, group, organizational psychological safety. Its influencing factors can be divided into individual factors, interpersonal factors, leadership features and organizational context four aspects;its main outcome variables conclude the knowledge sharing, voice, innovation, job involvement and job performance. Finally, the study points out the shortcomings of existing research and future research directions.
\end{abstract}

Keywords:Psychologicalsafety,Psychological contract, Organizational trust

\section{Introduction}

In the field of organization management and social psychology, how to cope and reduce organizational uncertainty and interpersonal risk from the individual psychological is a very important research topic. According to the uncertainty management theory (Lind \& van den Bos, 2002), the employee needs to deal with various aspects of uncertainty and interpersonal risk in the work environment. Uncertainty experience influences individual's cognition, emotion and behavior, even restricts to the individual's self-consciousness. Uncertainty and interpersonal risk experience is weary and worried, it will cause the individual to reduce the need and motivation of uncertainty and risk, and create interpersonal trust and safety on this basis (Thau, Bennett, Mitchell, \& Marrs, 2009). Psychological safety is a cognitive construct (Edmondson, 2002a), then we might argue about its concept.

\section{The concept of psychological safety}

The formal definition of psychological securitywas first described by Maslow in his hierarchy of needs as "a kind of feeling of confidence, safety and freedom detachment out fear and anxiety, in particular, it contains the feeling a person meet current and future needs "(Maslow, 1945).

Psychological safety perception in organization field originated in psychological climate(Wang Meiling, Li Shantian, 2007). 
Schneider(1975) put forward "climate is the individual abstract psychological perception for a particular event, condition and experience". James \& James(1989) thought that psychological climate refers to employees how cognize the influence work environment on their own welfare in psychology area. Yang Minxi (2002) viewed the psychological climate as individual level variables, "the process reaction of individual characteristics, involved in cognition, concept formation and the work environment". Employees might explain things, predict the possible results, and even take the next appropriate behavior according to their perceived psychological climate(Jones \& James, 1979). When employees see working environment be help for their own well-being, we can call it psychological safety, further, psychological safety refers to employees are aware of the high freedom to show themselves, don't worry about damage self-image, organizational status or career development.(Brown \& Leigh, 1996).

Schein \& Bennis(1965) earlier discussed psychological safety in workplace, main analyzed employees'psychological safetyduring organization change, pointed out"when organization changes, if members possessthe ability of change, they will feel safe" (quoted in Yang Minxi, 2002). In the study of employee engagement, Kahn(1990) also defined psychological safetyas"employees do not worry about self-image, position and negative impact of work, truly express themselves and show the different egos of different contexts". Then, Edmonson(1999) introduced psychological safety from the individual level to the group level, called as "team psychological safety", and defined as "when members engage in any risky action in a team, the implementation of these actions is safe, can be accepted by colleagues", she points out, psychological safety of staff is high when:(1)organizational members can speak one's mind freely; (2) the organization encouraged and allowed risk-taking; (3) organizational members trust and respecteach other; (4) organization members have the same beliefs and opinions for things. Team psychological safety emphasized team but team members, based on trust, similar cognitive and similar beliefs (Klimoski \& Mohammed, 1994; Walsh, 1995). Brown \& Leigh(1996) rise psychological safety from the individual level to the organizational level, he see"organizational psychological safety is a kind of employees' perceptions about organizational environment characteristics, including three aspects of perception: the support of management, clear job roles and allow for self-expression". Ling Bin (2010) thought psychological safety is a multi-hierarchy construct, namely individual, group and organizational level. 
Table 1 Definitions of psychological safety

\begin{tabular}{|c|c|c|}
\hline Levels & Authors & Definition \\
\hline \multirow[t]{5}{*}{ individual } & Maslow(1945) & $\begin{array}{l}\text { a kind of feeling of confidence, safety and freedom detachment out fear } \\
\text { and anxiety, in particular, it contains the feeling a person meet current } \\
\text { and future needs }\end{array}$ \\
\hline & $\begin{array}{l}\text { Schein \& Bennis } \\
(1965)\end{array}$ & $\begin{array}{l}\text { when organization changes, if members possess the ability of change, } \\
\text { they will feel safe }\end{array}$ \\
\hline & $\begin{array}{l}\text { Jones \& James } \\
(1979)\end{array}$ & $\begin{array}{l}\text { Employees might explain things, predict the possible results, and even } \\
\text { take the next appropriate behavior according to their perceived } \\
\text { psychological climate }\end{array}$ \\
\hline & $\begin{array}{l}\text { James } \quad \& \text { James } \\
(1989)\end{array}$ & $\begin{array}{l}\text { A kind of perceive when employees see working environment be help for } \\
\text { their own well-being }\end{array}$ \\
\hline & Kahn(1990) & $\begin{array}{l}\text { employees do not worry about self-image, position and negative impact } \\
\text { of work, truly express themselves and show the different egos of } \\
\text { different contexts }\end{array}$ \\
\hline \multirow[t]{4}{*}{ team } & $\begin{array}{l}\text { Klimoski et al } \\
(1994)\end{array}$ & based on trust, similar cognitive and similar beliefs \\
\hline & Edmonson(1999) & $\begin{array}{l}\text { when members engage in any risky action in a team, the implementation } \\
\text { of these actions is safe, can be accepted by colleagues }\end{array}$ \\
\hline & Yang Minxi(2002) & $\begin{array}{l}\text { Team member: (1) organizational members can speak one's mind freely; } \\
\text { (2) the organization encouraged and allowed risk-taking; (3) } \\
\text { organizational members trust and respect each other; (4) organization } \\
\text { members have the same beliefs and opinions for things. }\end{array}$ \\
\hline & Tynan(2005) & $\begin{array}{l}\text { Psychological safety is divided into self psychological safety } \\
\text { (self-perception of others is safe) and others psychological security } \\
\text { (communicating with others feel that they are safe) }\end{array}$ \\
\hline \multirow[t]{3}{*}{ organizational } & $\begin{array}{l}\text { Brown \& Leigh } \\
(1996)\end{array}$ & $\begin{array}{l}\text { organizational psychological safety is a kind of employees' perceptions } \\
\text { about organizational environment characteristics, including three aspects } \\
\text { of perception: the support of management, clear job roles and allow for } \\
\text { self-expression }\end{array}$ \\
\hline & May et al (2004) & Interaction with trust and openness in the work environment \\
\hline & Baer \& Frese (2003) & $\begin{array}{l}\text { A formal and informal organization management practices and } \\
\text { procedures, guide and support an open atmosphere and trustworthy in the } \\
\text { work environment }\end{array}$ \\
\hline
\end{tabular}

Source: This study

Psychological safety is often used as a index of employee psychological contract, organizational trust, when individuals feel interpersonal environment is trustworthy, psychological safety is also relatively strong
(Kahn, 1990). In the general level, psychological safety perception is regarded as an intermediate link between the organization characteristics and individual outcomes (such as employee attitudes, motivation, performance) (Edmondson, 2003; Li Rui, 2009). 


\section{The measurement of psychological safety}

At present, the measurement of psychological safety is mainly the 7 item scale by Edmondson(1999), it was originally designed for the measurement of team psychological safety: 1.If you make a mistake on this team, it is often held against you; 2.Members of this team are able to bring up problems and tough issues; 3.People on this team sometimes reject others for being different; 4.It is safe to take a risk on this team; 5.It is difficult toask other members of this team for help; 6.No one on this team would deliberately act in a way that undermines my efforts; 7.Working with members of this team, my unique skills and talents are valued and utilized. Many studies have referred this scale.

Brown \& Leigh(1996) developed the scale of organizational psychological safety, mainly expressed the degree that individuals perceived psychological safety in the organizational context. According to the dimensions, this scale included three subscales corresponding: support of management, clear job roles and allow for self-expression.

Tynan (2005) also developed the scale of psychological safety based on interpersonal interaction in workplace. It included two subscales, reliability is high. Among them, the self-psychological safety scale, a total of 7 items, all positive scored, Cronbach alpha coefficient is 0.93 ; others psychological safety scale, a total of 5 items, are reversely scored, Cronbach alpha coefficient is 0.82 .

Yang Minxi(2002) development team psychological safety scale sample as enterprises in Taiwan, a total of 19 items, five dimensions: speak one's mind freely, common belief, risk-taking behavior, respect each other and trust each other.

But for the individual psychological safety, the fitnessof above scale can be inadequate. Base on the related research of other scholars, Li Ning, Yan Jin(2007) revised 5 item scale from May, Gilson \& Harter (2004) and Edmonson (1999), reliability and validity is good.

\section{The influencing factors of psychological safety}

For individual psychological safety, the existing researchs mainlydiscuss the influencing factors of psychological safety from different angles and different levels, it generally can be divided into the following several aspects.

\subsection{Individual factors}

Studies of this aspect are limited, and mainly focus on the individual state characteristics.

May et al(2004) shows that, the individual's self-consciousness and psychological safety is negatively correlated, self-consciousness relates to how others perceive and evaluate us, this makes us cause an external cue, they tend to pay too much attention to the impressions they leave others and monitor social environment to take action, these often makes the individual psychological safety drop. 


\subsection{Interpersonal factors}

The relationship between employees and other people in the organization will influence the perception of psychological safety, the reason may be good interpersonal interaction is beneficial to reduce conflicts, eliminate the uncertainty, so that the psychological safety can be ensured (Kahn, 1990). Such as Kahn (1990), May et al (2004) view that interpersonal trust and support can improve employees' psychological safety.

\subsection{Leadership features}

Tynan(2005) pointed out, leadership behavior is the most effective predictor variables for employee psychological safety. Kahn(1990) also believe that management style is correlatedwith individual psychological safety, supportive and open style may play a promoting role on the latter. May et al(2004) have come to similar conclusions, supervisor support will promote employees' psychological safety. Walumbwa et al(2009) indicates that the moral leadership has a positive effect on subordinates' psychological safety, the prediction effect is very significant. They believed, moral leadership is often perceived as generous, subordinates' adventure and error also can be reasonable disposal, so the psychological safety will improve. Li Ning, Yan Jin(2007) and Li Rui (2009) focused on the negative leadership impact on employees' psychological safety, confirmed the negative effects of abusive supervision.

\subsection{Organizational contexts}

Some organizational contextual factors influence on individual psychological safety.
The most typical is organizational innovation and change, because in these situations, employee perceived external risk and threat increase, increasing the uncertainty, lead to psychological safety reduce. Wang Meiling, Li Shantian(2007) tested the relationship between organizational innovation and psychological safety, reached a similar conclusion.

\section{The Consequences variables of psychological safety}

About outcome variables of psychological safety, Scholars discussed widely and deeply, it can be roughly divided into the following several aspects.

\subsection{Knowledge sharing}

Scholars studied the relationship between psychological safety and knowledge sharing behavior. Zhang Yongjun(2010) find psychological safety is significant positive correlation with knowledge sharing willingness of employees, and plays a mediating role between learning goal orientation and performance avoidance orientation and knowledge sharing willingness. Zhang Pengcheng(2011) found that psychological safety not only has a positive effect on the employee's knowledge sharing behavior, but also mediates the relationship between charismatic leadership and knowledge sharing.

\subsection{Voice}

Van Dyne et al(2008) confirmed the mediating role of psychological safety between superior subordinate and employee voice behaviorrelationship. Liang et al(2008) also 
found that employees' psychological safetymight predict significant effect on promote and inhibit voice. Walumbwa \& Schaubroeck(2009) verified the mediating effect of psychological safety of the relationship between moral leadership and voice behavior. Zheng Renwei (2010) found that psychological safety plays a mediating role of positive relationship between people-organizations fit and voice behavior. Wu Weiku (2012) also confirmed its intermediary role between abusive supervision and voice behavior.

\subsection{Innovation}

The relationship between psychological safety and the employee's innovation behavior is clear. Zhang Pengcheng (2011) found that employee psychological safety is positive correlated with creativity. Long Jing and Wang $\mathrm{Li}(2011)$ take the acquisition of enterprise employees as the object, found that psychological safety plays a moderating role in the relationship perceived threat negative effect employees creativity.

\subsection{Job involvement}

Kahn(1990) pointed out that the psychological safety is one of the three psychological conditions to improve employee engagement (the other two are psychological meaning and psychological validity). May et al(2004) empirically found the psychological safety positive impact on job involvement. Li Rui(2010) found that psychological safety and supervisor trust fully mediate the relationship between perceived supervisor supportand job involvement.

\subsection{Job performance}

The relationship between psychological safety and job performance has been verified by many scholars. Brown et al(1996) proposed the first path between them, namely, psychological safety would improve employees' job involvement and then influence their work effort and job performance. The study of Edmondson(1999) can be regarded as the second paths, namely psychological safety will produce positive effect to enhance the learning behavior of employees, and then improve job performance. Li Ning (2007) has also confirmed this conclusion, they discovered two kinds of path (improvement innovation and workfocus) exists in the above relationship at the same time.

\section{Conclusions}

Although the discussion of psychological safety - - from definition, dimension classification, measurement to causal relationship-—were quite thorough and deep, but there are still some shortcomings in thecurrent study.

(1) The study of individual level of psychological safety is relatively few. The study of Edmondson(1999) is based on the team psychological safety, Brown \& Leigh(1996) discusses psychological safety climate in organization, this two scalesare the mainstream of current measurement, so the scholar concentrated in the two aspects of team and organization level when explore psychological safety. Some scholars also notice the level of the individual psychological safety to be involved, 
but on the whole, the degree of its attention and the richness of achievements are far less than the former two.

(2) The study of the negativeinfluencing factors of psychological safety is few. The current study of influence factor of psychological safety focuses on individual, leadership, organizational factors, and to explore the promotion to psychological safety from the positive point, and few studies consider from negative angle. Especially for the leadership behavior, the significance of negative leadership cannot be ignored, so it is very necessary to explore the relationship between negative leadership behavior and psychological safety of subordinate.

(3) The intermediary role of the level of the individual psychological safety is not enough. Corresponding with the previous two, although the current study mainly consider psychological safety as the intermediate link of organization related variables antecedents and consequences relationship, but also more concentrated in the team and organizational level, for the individual level,it is still not too much.

In view of the above problems, the further study should focused on the individual level of psychological safety perception, and discusses its passive effect on employees' psychological safetyfrom negative leadership angle, and to test intermediary effect of the psychological safety, in order to further deepen and enrich the empirical evidence related field.

\section{Acknowledgement}

This research was financially supported by the National Social Science Foundation of China (Grant NO. 12AJY005) and the Fundamental Research Funds for Beifang Univesity of Nationalities (Grant NO.2014XYS33).

\section{References}

[1]Baer M \& Frese M. 2003. Innovation is not Enough: Climates for initiative and psychological safety, process, innovation and firm performance[J]. Journal of Organizations Behavior, 24: 45-68.

[2]Brown S P \& Leigh T W. 1996. A new look at psychological climate and its relationship to job involvement, effort, and performance[J]. Journal of Applied Psychology, 81: 358-368.

[3]Brown S P \& Leigh T W. 1996. A new look at psychological climate and its relationship to job involvement, effort, and performance[J]. Journal of Applied Psychology, 81: 358-368.

[4]Edmondson A. 1999. Psychological safety and learning behavior in work teams[J]. Administrative Science Quarterly, 44: 350-383. [5]Jones A P \& James L R. 1979. Psychological Climate: Dimensions and Relationships of Individual and AggregatedWork Environment Perceptions[J]. Organizational Behavior and Human Performance, 23: 201-250.

[6]Kahn W A. 1990. Psychological conditions of personal engagement and disengagement at work[J]. Academy of Management Journal, 33: 692-724.

[7]Maslow A H, Hirsh E, Stein M \& Honigmann I. 1945. A clinically derived test for measuring psychological security-insecurity[J].Journal of General Psychology, 33: 21-41.

[8]Tynan R. 2005. The effects of threat sensitivity and face giving on dyadic psychological and upward communication[J]. 
Journal of Applied Social Psychology, 35: 223-247.

[9]Walumbwa F O \& Schaubroeck J. 2009. Leader personality traits and employee voice behavior: Mediating roles of ethical leadership and work group psychological safety[J]. Journal of Applied Psychology, 94(5): 1275-1286.

[10]Edmondson, A. C. (2002a). Managing the risk of learning:Psychological safety in work teams. In West, M., Tjosvold,D., \& Smith, K
(Eds.), International Handbook ofOrganizational Teamwork (pp. 1-38). London: Blackwell.

[11]May, D. R., Gilson, R. L., \& Harter, L. M. (2004). Thepsychology condition of meaningfulness, safety andavailability and the engagement of the human spirit atwork. Journal of Occupational and OrganizationalPsychology, 77, 11-37. 